\title{
ANÁLISE DA APLICAÇÃO DAS NORMAS REGULAMENTADORAS EM CANTEIROS DE OBRAS DE PEQUENO PORTE NO MUNICÍPIO DE BEBEDOURO, SP
}

\author{
Gustavo Henrique Vital Gonçalves (Universidade Federal de São Carlos) \\ guvital1@hotmail.com \\ José da Costa Marques Neto (Universidade Federal de São Carlos) joseneto@ufscar.br \\ Leonardo Brian Gonçalves da Rocha (Centro Universitário Unifafibe) 11.brian@ hotmail.com
}

\section{RESUMO}

A construção civil é um dos setores mais produtivos, porém, com alto índice de acidentes de trabalho e de ocorrências fatais. Uma das principais causas dos acidentes continua sendo a falta de consciência profissional por parte de empregadores e empregados quanto à aplicação das Normas de Segurança do Trabalho aos quais podem evitar, prevenir e se antecipar aos acidentes. Nas obras de pequeno porte, com número inferior a 20 funcionários, estes aspectos devem piorar, por não terem a obrigação da implantação de medidas de controle e prevenção de segurança, pela alta rotatividade da mão de obra e pela informalidade e terceirização dos empregados, impossibilitando um trabalho efetivo a médio e longo prazo nesta área.

Palavras-chave: Segurança do trabalho. Obras de pequeno porte. Normas regulamentadoras.

\section{INTRODUÇÃO}

$\mathrm{Na}$ história do Brasil, a construção civil representa um setor com ampla absorção de mão de obra, a qual oferta setores para trabalho, com poucas restrições para o recrutamento do trabalhador. É um setor rentável e de grande importância no cenário econômico brasileiro (TAKAHASHI, et al. 2012). Segundo Moraes (2017), dados da Confederação Nacional da Indústria (CNI), apontam que o setor passou por um alto crescimento, impulsionado pelo equilíbrio financeiro do país e, também, por políticas sociais voltadas para a habitação, aumentando a capacidade aquisitiva da classe média e permitindo o acesso a bens duráveis.

Mesmo sendo considerado um dos setores que mais utiliza mão de obra, há questões que a área da construção civil que tem por se tornar frequente, como a instabilidade na 
qualidade técnica de seus trabalhadores e a não consolidação do processo industrial (MORAES, 2017).

Diante do atual cenário, a segurança e saúde no trabalho busca incorporar-se ao cotidiano, independentemente do tamanho dos canteiros de obra das construções e não apenas com o cumprimento exigido pela Lei, mas também pela concepção e importância dos resultados determinados por estas ações, como resguardar a vida do empregado, preservando sua integridade, melhorar os custos, elevar a produção, baixar o número de acidentes, entre outros (MORAES, 2017).

Nas obras de pequeno porte a presença de técnicos de segurança acaba não sendo um procedimento exigido, sendo assim, cabe ao engenheiro responsável evitar possíveis acidentes (HENRIQUE et al., 2017).

O objetivo deste estudo é avaliar as condições do trabalho apresentado em algumas construções de pequeno porte no município de Bebedouro-SP, e analisar nestas a aplicação das Normas Regulamentadoras NR-6; NR-17; NR-18 e NR-35, diante do que é estabelecido por cada uma delas.

\section{REFERENCIAL TEÓRICO}

\subsection{Construção civil}

A construção civil e a humanidade estão interligadas, uma vez que o ato de construir é uma necessidade para o desenvolvimento da sociedade e de sobrevivência para o ser humano. Tal setor é de extrema importância na economia brasileira, pois gera emprego e renda, diretamente ou indiretamente, contribuindo para o crescimento do país (JESUS et al., 2018).

Constituído economicamente como um setor produtivo, o fato é que ainda apresenta dados negativos quanto a questão de segurança, mão de obra e principalmente trabalhos informais (TAKAHASHI et al., 2012).

\subsection{Características das obras de pequeno porte}

As pequenas empresas atuam na execução de obras de curto prazo e são formadas por um número enxuto de profissionais viabilizando uma comunicação fácil, rápida e de pouco tempo na aplicação do desenvolvimento da obra. Estas obras são menos fiscalizadas e, por 
serem em curto prazo, tendem aplicar menos os parâmetros de seguranças e prevenção de acidentes (SIRICHUK, 2013).

Outra particularidade que corrobora para que a construção civil seja vista com um olhar mais apurado são os impactos ambientais causado devido ao consumo de recursos naturais, a produção continua de resíduos e aos numerosos acidentes de trabalho (ARAÚJO; DOMINGUES JÚNIOR, 2018).

\subsection{Segurança do trabalho e as Normas Regulamentadoras (NR's)}

As Normas Regulamentadoras foram baseadas em procedimentos técnicos que fala de uma série de informações de processos administrativos, planejamento e organização (ARAÚJO; DOMINGUES JÚNIOR, 2018). A Norma Regulamentadora NR-18 responsável pelas Condições e Meio Ambiente de trabalho na indústria da Construção, reconhece que todo tipo de obra deve cumprir regras e, assim, estabelece medidas preventivas com a finalidade de minimizar acidentes e doenças ocupacionais (BRASIL, 1978).

No entanto, a diminuição dos acidentes na área da construção civil, até mesmo nos países desenvolvidos, não é algo de fácil solução, mesmo diante do desenvolvimento tecnológico dos últimos anos e do progresso da legislação que em especial, no Brasil ocorreu com a autorização da portaria $\mathrm{n}^{\circ} 3214$, de 08 de junho de 1978, criando as Normas Regulamentadoras (BENITE, 2004).

Os acidentes de trabalho são associados ao responsável técnico pela obra, seja ele um Engenheiro ou Arquiteto, mas que oferece quadros de trabalho de forma insegura e também a empregados omissos que cometem atos perigosos (MEDEIROS; RODRIGUES, 2001).

Para tanto, o método de Análise Preliminar de Riscos (APR) tem como base identificar acontecimentos inseguros, causas e resultados, para assim, determinar meios de prevenção através da etapa de construção e criação de um novo sistema, tendo como objetivo analisar a fase operacional e prescrever os riscos presentes. Com certo número relevante de acontecimentos, pode se apontar métodos de controle de riscos (BRASIL, 1978).

A Norma Regulamentadora 6, responsável pela utilização pelos Equipamentos de Proteção Individual, prescreve normativas a serem seguidas de modo à asseguras a segurança e saúde do trabalhador (BRASIL, 1978).

Quanto a Norma Regulamentadora NR-17, é descrito que ela deve visar estabelecer parâmetros que possam permitir a adaptação das condições de trabalho às características psicofisiológicas dos trabalhadores, dito isto, de modo que possa proporcionar o máximo de 
conforto, segurança e desempenho. Quanto as condições de trabalho, incluem aspectos relacionados ao levantamento, transporte e descarga de materiais, isto é, toda e qualquer atividade que se relacione a algum risco Ergonômico (BRASIL, 1978).

A Norma Regulamentadora NR-18 que prescreve sobre as Condições e Meio Ambiente de Trabalho na Indústria da Construção, mesmo que reúna e estabeleça Leis básicas para assegurar a segurança, ela não elimina o fato de os trabalhadores presentes na prática construtiva, estarem expostos a riscos de acidentes, pois as mesmas nem sempre são suficientes para evitá-los (BRASIL, 1978).

Entretanto, a Norma Regulamentadora NR-35 responsável pela segurança do trabalho em altura, enfatiza que na etapa do planejamento deve-se levar em conta a melhor opção de execução do procedimento, considerando realizar este sem que o trabalhador seja exposto à altura, evidenciando a intenção da segurança do trabalhador, isto é, sempre que seja possível a execução de uma atividade sem que o trabalhador seja exposto a sofrer um risco de queda por realizar o trabalho em altura, o mesmo deve ser levado em consideração diante do planejamento (BRASIL,1978).

\subsection{Equipamentos de Proteção Individual e Coletiva em obras da Construção Civil}

Para que ocorra o uso correto dos EPI's e EPC's nas obras, os órgãos responsáveis pela fiscalização estão promovendo cartazes, folders com finalidade para que os trabalhadores se conscientizem a terem o maior cuidado em relação a acidentes de trabalho (KELLYSANTOS; ROZEMBERG, 2006).

Aos empregados regidos pela Consolidação das Leis do Trabalho-CLT, deverá ser garantido à proteção da integridade e moral do trabalhador, garantindo uma boa condição de trabalho, diminuindo o ambiente inseguro (ALVES, 2013).

De acordo com Moraes (2017) uma lista básica de EPI's importantes a serem utilizados nas obras, são eles:

a) Proteção à cabeça: capacete de segurança 1/2 aba, óculos de segurança contra impactos, protetor auricular;

b) Proteção aos membros superiores: avental, luvas, protetor solar;

c) Proteção aos membros inferiores: calçado de segurança com biqueira;

d) Proteção geral: uniformes, cinturão de segurança tipo paraquedista, trava-quedas, colete refletivo. 
Conforme a NR-6 (1978) “A empresa é obrigada a fornecer aos empregados, gratuitamente, EPI adequado ao risco, em perfeito estado de conservação e funcionamento".

Para os trabalhadores, deve ser realizado cursos de capacitação para que, assim, seja promovido o conhecimento sobre as Normas de segurança, domínio e compreensão das equipes sobre o valor da segurança no trabalho, a inspeção dos equipamentos de combate a incêndio, primeiros socorros, além da fiscalização e entrega dos EPI's aos funcionários, com consenso dos riscos que existem, conforme a NR-18 (ALVES, 2013).

Já o Equipamento de Proteção Coletiva, considerado como um dispositivo fixo ou móvel tem como finalidade cuidar da integridade física e a saúde dos trabalhadores que estão exercendo a sua função em um determinado local (BELTRAMI; STUMM, 2018).

\section{METODOLOGIA}

Para a pesquisa e realização deste trabalho, o método usado foi um estudo bibliográfico qualitativo, através de literatura corrente sobre artigos, livros e teses, além de visitas de campo.

O estudo de caso foi desenvolvido em 9 canteiros de obras no município de Bebedouro-SP, deste modo, realizou-se a coleta e o levantamento de dados diretamente no local através de visitas técnicas. As visitas foram realizadas sem agendamento, visto que deste modo possa ser obtido um resultado mais preciso para a pesquisa, destacando que nestas condições o canteiro de obra, os trabalhadores e os responsáveis técnicos estejam despreparados para uma possível visita ou fiscalização.

Nas visitas foram realizadas e arquivadas observações através de fotos, para identificar e analisar o modo em que o canteiro de obra é apresentado, se está dentro dos padrões descritos pelas Normas estabelecidas para o estudo de caso realizado, tal como, o modo como os trabalhadores exercem as suas funções, se está de forma correta e segura, dito isto, a NR-6; NR-17; NR-18 e NR-35; ao qual definimos ser normativas mais específicas para área da Construção Civil e também para as características de obras a serem visitadas, para assim, posteriormente realizar a discussão sobre os resultados obtidos.

Essa avaliação visual foi fundamentada pelas Normas Regulamentadoras, sendo a principal Norma a ser considerada neste trabalho a NR-18 que diz respeito as Condições e Ambiente de Trabalho na Indústria da Construção Civil.

\section{RESULTADOS E DISCUSSÃO}


Durante o período entre Março e Maio de 2019, foram visitados 9 canteiros de obras no município de Bebedouro-SP, obras como a construção e reforma de residências, edificações com áreas superiores a 500 $\mathrm{m}^{2}$, tais como, reforma de fachada e construção de um barracão, entretanto, nenhum canteiro de obra possui número superior a 15 trabalhadores durante a sua execução.

A seguir, apresenta-se os resultados obtidos e a análise e discussão referente a cada canteiro.

\section{- Canteiro de obra}

O primeiro canteiro de obra visitado está localizado no centro da cidade de Bebedouro-SP. Trata-se de uma reforma de fachada e da lateral do edifício, uma paróquia, que irá obter uma pequena expansão e reforço de ambos.

A obra possui 14 trabalhadores, no local no momento da visita havia 8 trabalhadores, junto de um mestre de obra, acompanhando e executando a mesmo. Dentre os serviços executados, trabalho em altura e trabalho térreo.

Analisando o trabalhador na Figura 3, percebe-se que ele estava executando a vedação externa da edificação. Neste caso o trabalhador deveria estar utilizando EPI apropriado (cinturão de segurança tipo paraquedista).

Figura 3. Revestimento externo da alvenaria na fachada da edificação

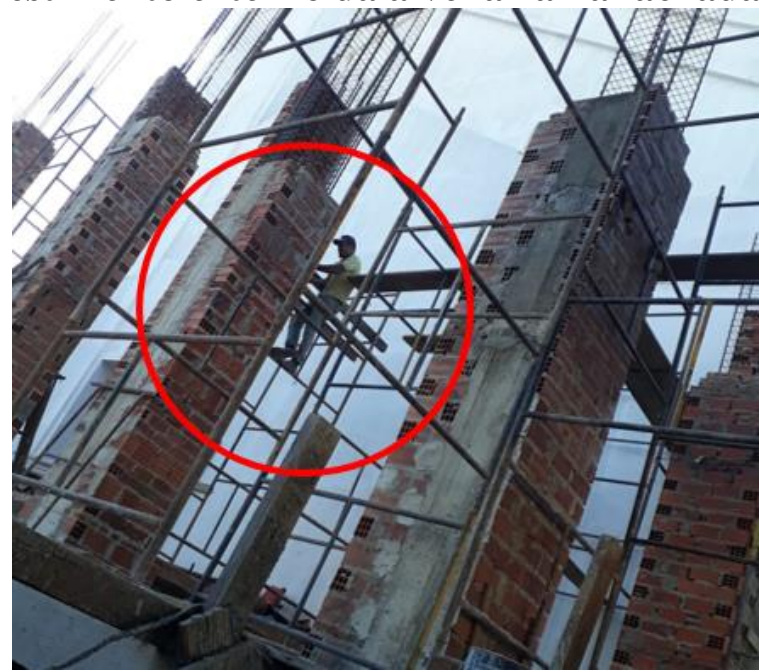

Fonte: próprio autores 
É prescrito pela Norma referente ao trabalho em altura NR-35, especificações sobre a utilização de cinturão tipo paraquedista, ao qual, é classificado como um Sistema de Proteção Individual contra Quedas (SPIQ).

Segundo a NR-35 (2012) "35.5.9. No SPIQ de retenção de queda e no sistema de acesso por cordas, o equipamento de proteção individual deve ser o cinturão de segurança tipo paraquedista."

\section{- Canteiro de obras 2}

No próximo canteiro de obra, localizado em um condomínio residencial, é identificado a realização de um trabalho em altura, mas assim como no canteiro de obras 1 , o trabalhador não segue as diretrizes estabelecidas pela NR-35 - Trabalho em altura.

Nesta obra percebe-se dois pontos de atenção, o primeiro, são duas tábuas na vertical podendo causar acidentes por risco de queda, a segunda demonstra o trabalhador executando o serviço acompanhado de alguns EPI's como capacete, luvas, no entanto, para o trabalho realizado em altura, falta a utilização de um ponto de ancoragem e durante a execução do serviço, deve-se utilizar EPI's específicos, tal como: cinto de segurança tipo paraquedista, talabarte, ou seja, com objetivo de transmitir segurança ao trabalhador.

A Figura 4, demonstra os pontos citados anteriormente.

Figura 4. Execução de trabalho em altura

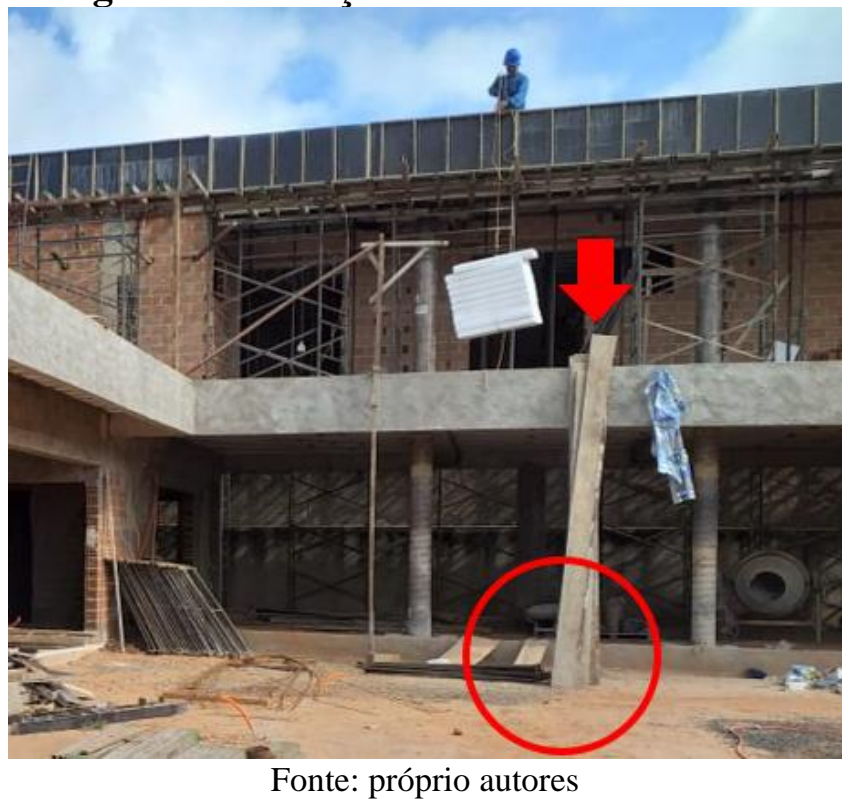


Assim, o uso do cinto de segurança nas atividades em altura é fundamental na prevenção de eventuais quedas, além de deixar o trabalho mais seguro.

Já o talabarte, trata-se de uma espécie de extensão do cinto, constituído por uma fita com um ponto de ancoragem, ao qual, o torna essencial. O ideal é que essa ancoragem seja posicionada de modo que o trabalhador consiga se prender antes de acessar a situação de perigo. Dependendo da situação, apenas um ponto de ancoragem não é suficiente para garantir a segurança.

A Figura 5 apresenta outra vista do trabalhador executando sua atividade, deste modo, pode ser identificado de forma mais explícita a falta de EPI, podendo assim o trabalhador se desequilibrar e sofrer uma queda.

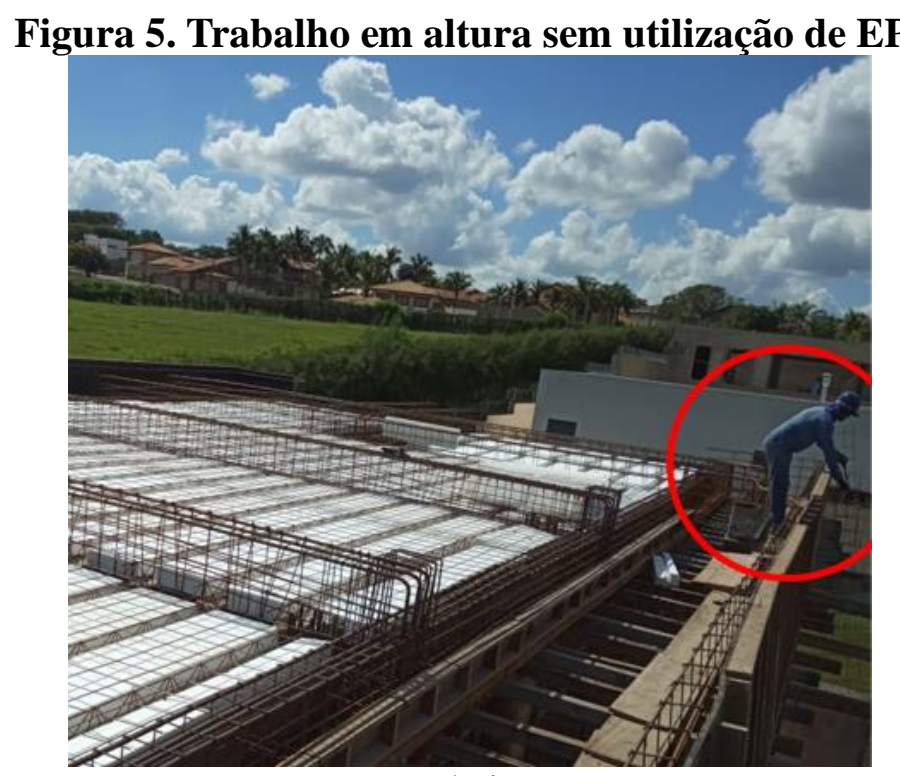

Fonte: próprio autores

\section{- Canteiro de obras 3}

Neste canteiro de obra que fica localizado no bairro Jardim Luciana, onde foi observada uma reforma de fachada de uma residência, com a presença de 3 trabalhadores para execução da obra e com a ausência de um responsável técnico.

Pode ser identificada na Figura 6 a improvisação do trabalhador, subindo em um tijolo para executar a atividade e também falta da utilização de EPI's, como capacetes, óculos e luvas, ao qual são indispensáveis em um canteiro de obras, mesmo em uma obra de pequeno porte. 


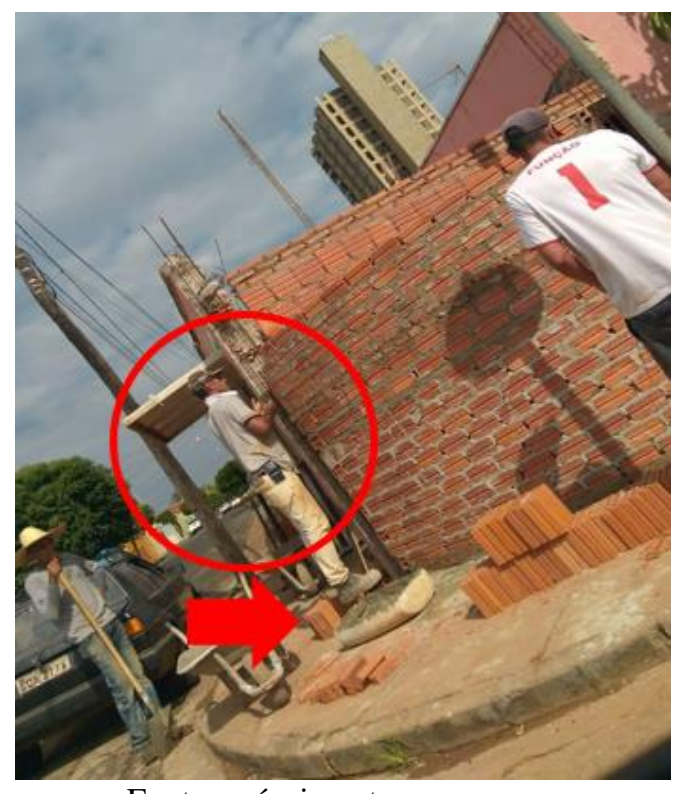

Fonte: próprio autores

A falta de acompanhamento de um Engenheiro ou até mesmo um técnico de segurança, acaba por tornar o ambiente de trabalho um local perigoso e com grandes possibilidades de acontecer acidentes.

\section{- Canteiro de obras 4}

Este canteiro de obras visitado está em um condomínio residencial. Nele está sendo realizada a construção de uma residência com 1 pavimento térreo, a obra conta com um grupo de 11 trabalhadores, dentre eles pedreiros e ajudantes, com a exceção de um Engenheiro responsável pela obra. Durante o processo de construção, pode ser identificado o modo como o trabalhador faz o carregamento de uma peça de andaime, com a sua postura incorreta (curvado), por conta do excesso de peso para o transporte manual.

Segundo a NR-17 (1978) “17.2.2. Não deverá ser exigido nem admitido o transporte manual de cargas, por um trabalhador cujo peso seja suscetível de comprometer sua saúde ou sua segurança".

Deve ser destacado também a não utilização dos EPI's, como luvas, um equipamento de grande importância para a execução de diversas atividades.

$\mathrm{Na}$ Figura 7, podemos identificar todos os pontos analisados. 


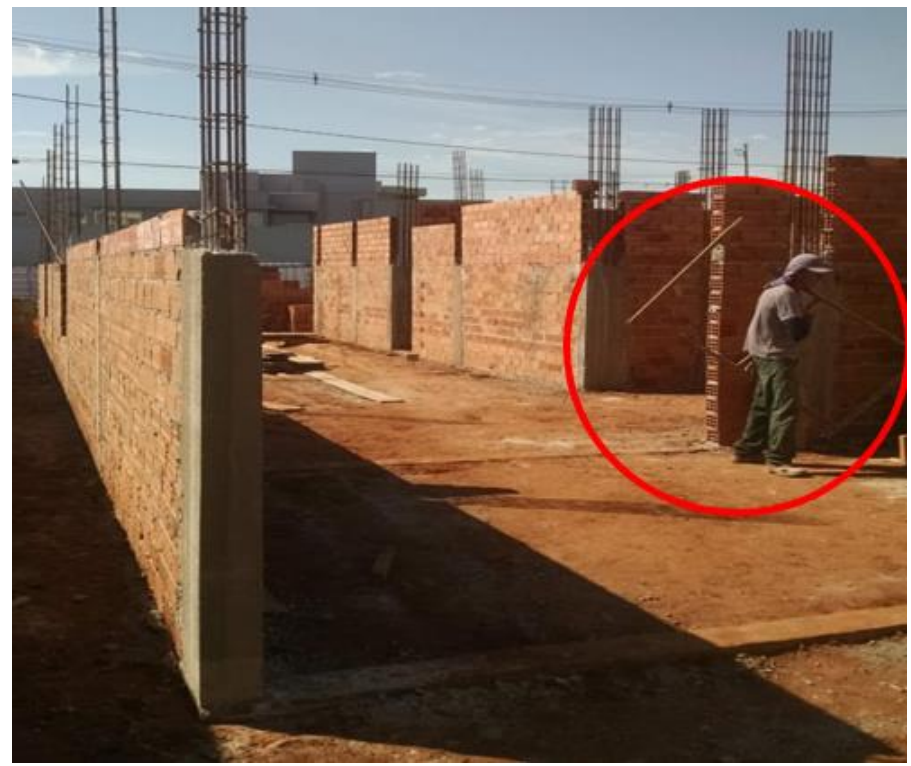

Fonte: próprio autores

Este canteiro de obra encontra-se cercado por tapumes.

Segundo a NR-18 (1978) "18.30.2 Os tapumes devem ser construídos e fixados de forma resistente, e ter altura mínima de 2,20m (dois metros e vinte centímetros) em relação ao nível do terreno".

Na Figura 8, pode ser observado o tapume ao fundo, assim como estabelecido pela Norma Regulamentadora, NR-18.

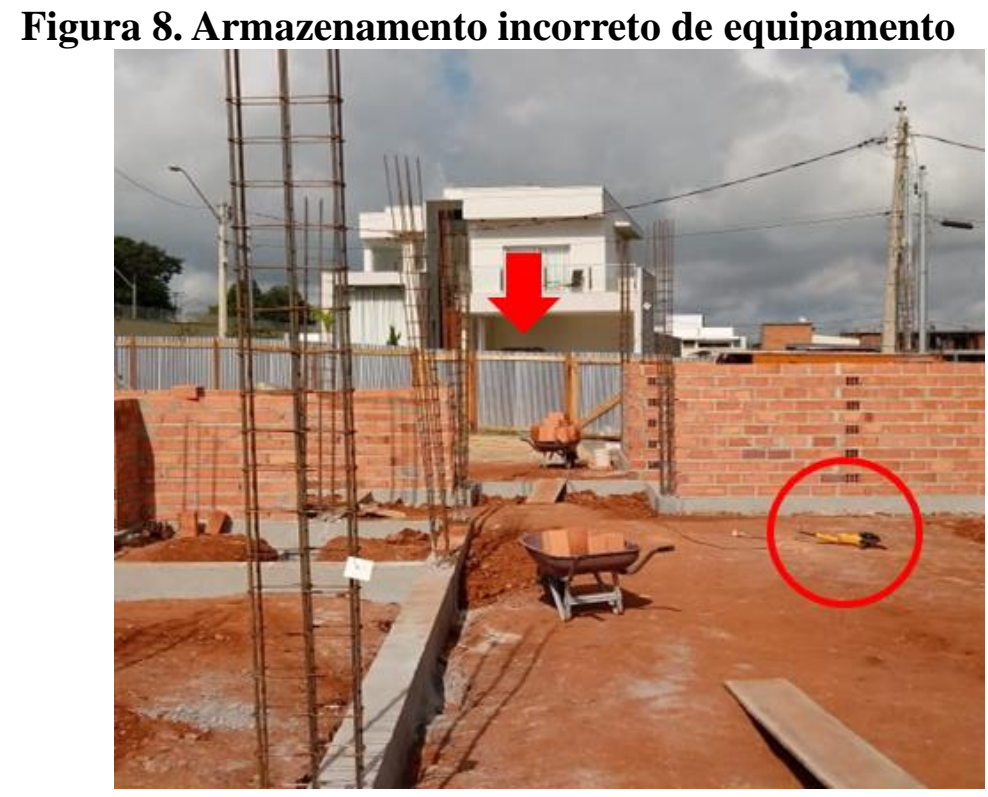

Fonte: próprio autores

Havia uma esmerilhadeira pneumática no chão, considerado um risco mecânico que pode causar acidente, onde deveria ser trocado por uma serra poli corte, a qual seria mais seguro e adequado para execução construtiva de uma residência. 


\section{- Canteiro de obras 5}

O próximo canteiro visitado está localizado no bairro Jardim Primavera, se trata uma reforma em uma residência. Durante o procedimento de revestimento da estrutura, que por sua vez também é realizado em altura, pode ser destacado que o trabalhador, durante a execução do serviço, não utiliza os EPI's necessários para sua segurança, dentre eles, luvas, capacete, óculos.

A altura da parede de alvenaria em relação ao corpo do trabalhador é superior a $2 \mathrm{~m}$, deste modo, a Norma Regulamentadora, NR-35, estabelece que o mesmo deve-se beneficiar de instrumentos de ancoragem ou até mesmo utilizar apoio de um andaime (desde que esteja de acordo com o que é prescrito pela norma responsável pelas estruturas de apoio), e somente depois executar sua atividade com segurança.

A Figura 9 demonstra o trabalhador executando a sua atividade e também a análise discutida anteriormente.

Figura 9. Improviso de apoio para trabalho em altura superior à 2 metros

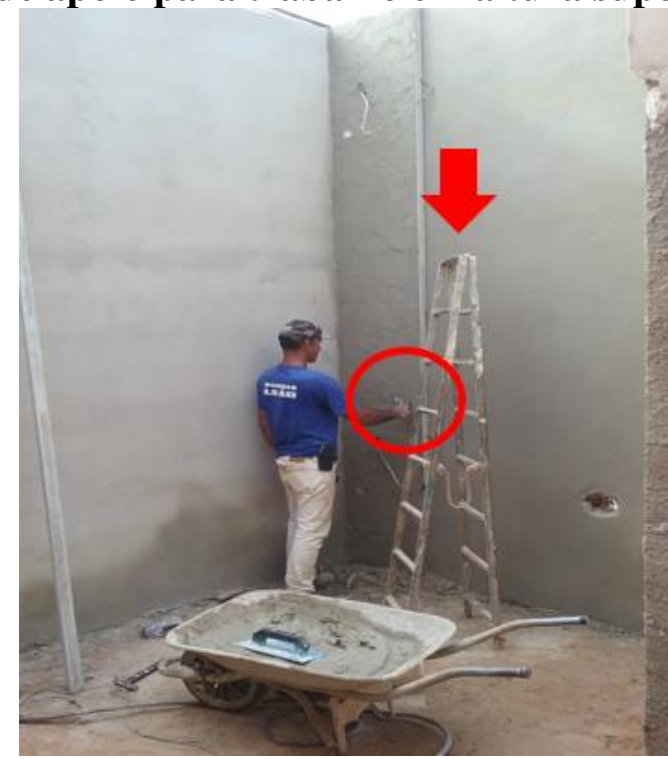

Fonte: Próprio autores

- Canteiro de obras 6

Durante a visita deste canteiro de obras que também foi realizado em uma construção no bairro Jardim Primavera e, que apresentava um número pequeno de trabalhadores, sendo 4 no local, observa-se um trabalhador rebocando a parede de alvenaria, durante o processo de 
revestimento. Para atingir um ponto superior à sua altura, utilizou-se do apoio de um andaime para executar o procedimento construtivo. Assim como mostra na Figura 10.

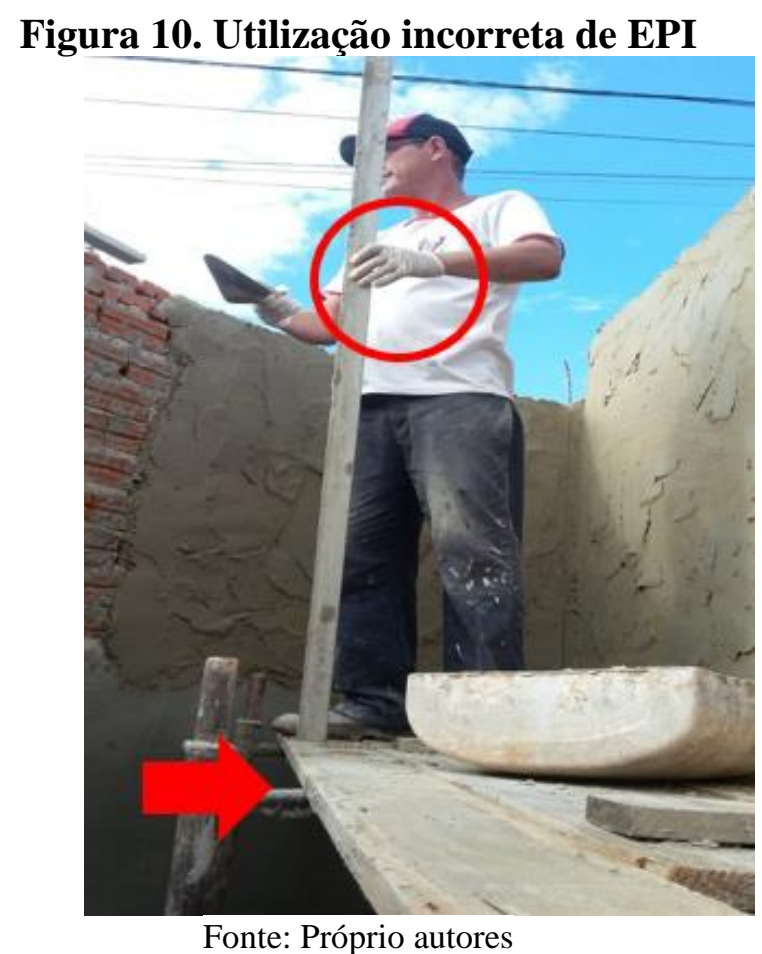

Segundo a NR-18 (1978) "18.15.1. O dimensionamento dos andaimes, sua estrutura de sustentação e fixação, deve ser realizado por profissional legalmente habilitado", ou seja, que deverá especificar e dimensionar de modo a suportar com segurança as cargas de trabalho que a estrutura estará sujeita.

Dentre os EPI's utilizado pelo trabalhador apresentado anteriormente na Figura 10, pode ser identificada a utilização de luvas cirúrgicas, não indicadas para o trabalho em construções. Nota-se também que não utiliza nenhum Equipamento de Proteção Individual, por exemplo óculos, capacete, entre outros.

\section{- Canteiro de obras 7}

Neste canteiro visitado, que está localizado no bairro São Fernando. Demonstra um trabalhador preparando a argamassa que será utilizada para executar o revestimento das paredes de alvenaria internas de uma residência. Para realizar o procedimento, nota-se a não utilização de nenhum EPI apropriado, como por exemplo, uso de luvas e de óculos, assim como é visto na Figura 11. Essas irregularidades podem causar acidentes. 


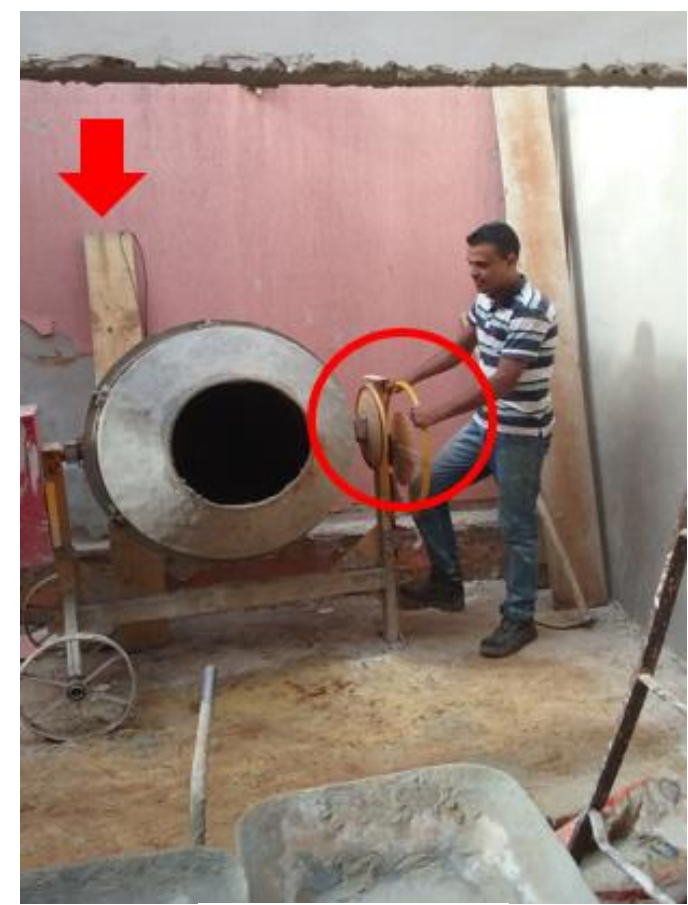

Fonte: Próprio autores

\section{- Canteiro de obras 8}

Neste próximo canteiro de obra, localizado no bairro Jardim Menino Deus I. É realizada a construção da cobertura na garagem e também a troca de piso interno da residência, dito isto, a obra conta com um grupo de 5 trabalhadores, no qual destacamos a falta de acompanhamento de um responsável técnico, como o Engenheiro ou Arquiteto.

Durante a execução da atividade de desplacamento do antigo piso, observa-se, a falta de EPI's para o procedimento que está sendo executado, como a utilização de luvas, capacete e óculos. Óculos que seria de suma importância, visto que, algum resíduo das placas de madeira poderia se soltar e acertar seu rosto, ocasionando um acidente.

A Figura 12 apresenta todos os pontos citados.

Figura 12. Realização de atividade na obra sem utilização de EPI 


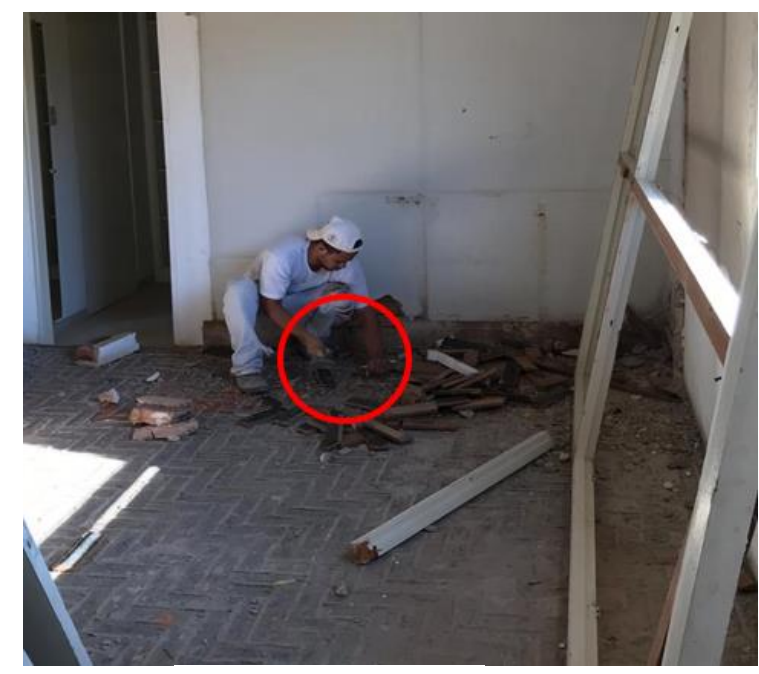

Fonte: Próprio autores

\section{- Canteiro de obras 9}

No canteiro de obras 9 , localizado em uma fazenda nas proximidades da cidade, está sendo realizada a construção de um barracão para o armazenamento de maquinários para caminhões. Com dimensões de $65 \mathrm{~m}$ de comprimento e $40 \mathrm{~m}$ de largura, a obra conta com um grupo de 15 trabalhadores.

Na Figura 13 pode ser identificado na fundação da estrutura, após ter sido preenchida com concreto, junto de gabaritos para o acompanhamento da estrutura de modo a manter a estrutura linear de acordo como foi previsto e especificado pelo projeto.

Figura 13. Esperas de vergalhões de aço na fundação sem proteção

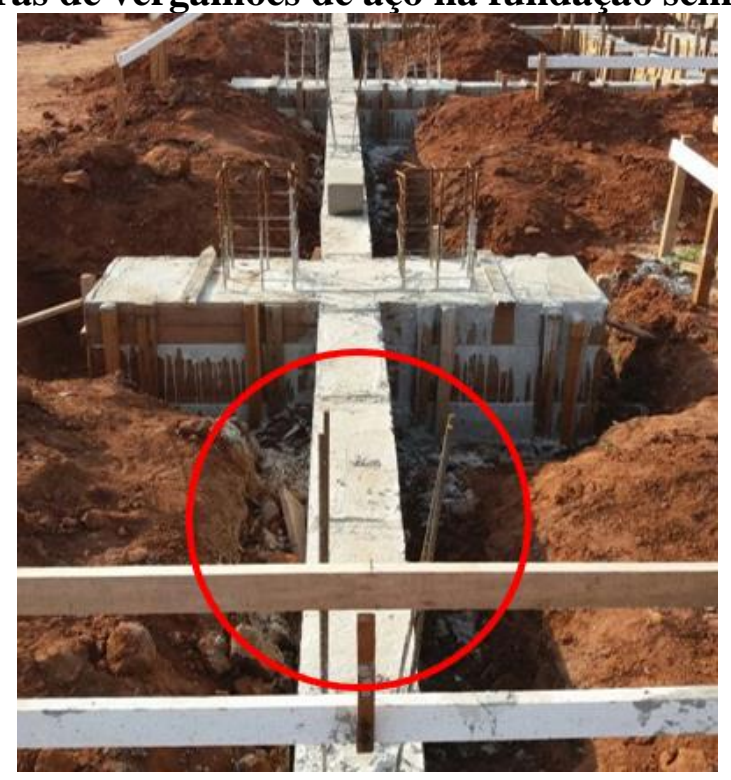

Fonte: Próprio autores 
Entretanto, foram identificadas as esperas dos vergalhões sem proteção na ponta, assim proporcionando risco de acidente no local, como perfurações. Segundo a NR-18 (1978) “18.8.5. É proibida a existência de pontas verticais de vergalhões de aço desprotegidas".

Para a situação é recomendado pela norma à utilização de protetores para vergalhões de aço, protetores que são encaixados em qualquer ferragem que esteja exposta na obra. Assim como pode ser demonstrado na Figura 14.

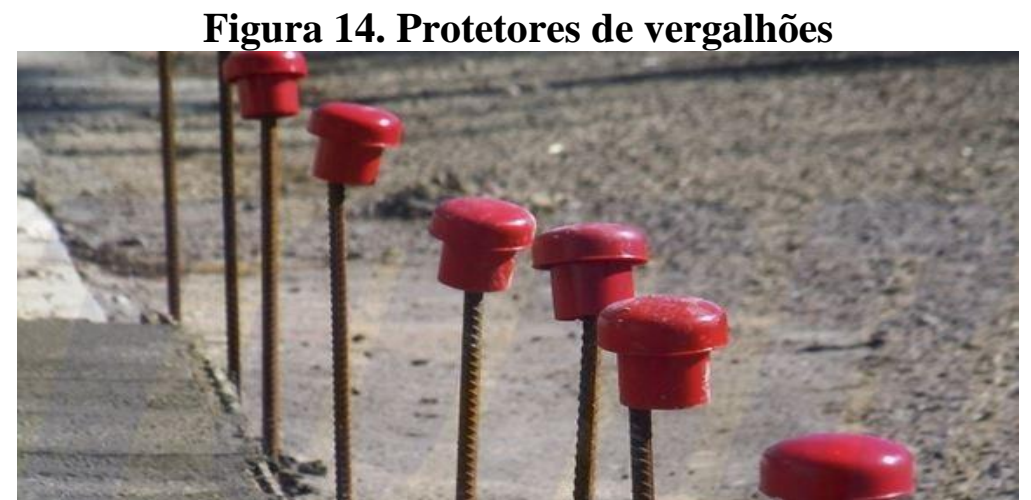

Fonte: Disponível em: <https://www.upequipamentos.com.br/produto/106/protetor-paravergalhao?gclid=cjwkcajwnrjrbrameiwaxscc41q3ka6kkyput9dya0dgrqhuu0nsasa4yk76os4a4ropjwshz04ihocix mqavd_bwe >

\section{CONCLUSÃO}

Através do estudo bibliográfico realizado e das pesquisas de campo, percebe-se que as empresas responsáveis por executar obras de pequeno porte preferem colocar a vida dos seus trabalhadores em perigo, economizando em medidas e precauções necessárias à segurança e sofrer os prejuízos, do que investir na prevenção.

A partir do conhecimento adquirido com a realização do trabalho, constatou-se a necessidade de investimentos na qualificação de funcionários, em treinamentos adequados às funções e na implantação dos programas de segurança nos canteiros de obras.

Com o desenvolvimento do questionário analisado no estudo de caso foi possível demonstrar que ainda há muita desconformidade nos canteiros de obras no que diz respeito à aplicação das normativas que envolvem a Segurança e Saúde do trabalhador, o que poderia contribuir para minimizar a exposição dos riscos de acidentes aos trabalhadores.

Conclui-se que dentre as obras de pequeno porte visitadas na cidade de Bebedouro-SP, na maioria das vezes não possuem profissional habilitado para orientar seus trabalhadores nas suas determinadas funções na obra, e estes tendem a não utilizar nenhum equipamento de 
proteção individual ou coletiva, e esses quesitos de segurança resultam em procedimentos que colocam a segurança desses trabalhadores em risco. A eficácia da segurança do trabalho na construção civil é feita através de dois pilares: a prevenção e a conscientização dos colaboradores envolvidos.

Por fim, uma análise mais aprofundada deve ser realizada em cidades com uma infraestrutura e habitação maior referente a do estudo, para assim verificar se os resultados obtidos se assemelham ou distinguem, visto que, a fiscalização e prevenção da segurança dos trabalhadores pode não ser coincidente com a do trabalho apresentado.

\section{REFERÊNCIAS}

ALVES, P. R. M. A importância dos EPIs na qualidade de vida dos funcionários de uma empresa madeireira. FACIDER-Revista Científica, v. 4, n. 4, 2013.

ARAÚJO, P. M. de; DOMINGUES JÚNIOR, R. P. Segurança do trabalho na construção civil: medidas de proteção em canteiros de obras. Revista Cientifica Multidisciplinar Núcleo de Conhecimento, v.11, p.68-80, 2018.

BELTRAMI, M.; STUMM, S. EPI e EPC. 1. ed. Curitiba: IFP, 2013.

BENITE, A. G.. Sistema de gestão da segurança e saúde no trabalho para empresas construtoras. 2004. Tese de Doutorado. Universidade de São Paulo.

BRASIL. Ministério do Trabalho e Emprego. NR- 6 Equipamento de Proteção Individual EPI, 1978. Disponível em: < http://www.guiatrabalhista.com.br/legislacao/nr/nr6.htm>. Acesso em: 26 de nov. de 2019.

BRASIL. Ministério do Trabalho e Emprego. NR-17 Ergonomia, 1978. Disponível em: < http://www.guiatrabalhista.com.br/legislacao/nr/nr17.htm> Acesso em: 26 de nov. de 2019. 
BRASIL. Ministério do Trabalho e Emprego. NR-18 Condições e Meio Ambiente de Trabalho na Indústria da Construção, 1978. Disponível em: < http://www.guiatrabalhista.com.br/legislacao/nr/nr18.htm >. Acesso em: 24 de out. de 2019.

BRASIL. Ministério do Trabalho e Emprego. NR-35 Trabalho em altura, 2012. Disponível em: 〈http://trabalho.gov.br/images/Documentos/SST/NR/NR35.pdf>. Acesso em: 24 de out. de 2019.

HENRIQUE, M. B.; FEITOSA, M. F.; ARAUJO, G. L. Acidentes nos canteiros de obras da construção civil no brasil. Anais do Seminário Científico da FACIG, n. 1, 2017.

JESUS, A. A. Comportamento Histórico no Brasil da Indústria da Construção Civil e suas Atuais Perspectivas. Revista Científica Multidisciplinar Núcleo do Conhecimento, ano 03, v. 05 , n. 3 , p. $87-95$, jul. 2018

KELLY-SANTOS, A.; ROZEMBERG, B. Estudo de recepção de impressos por trabalhadores da construção civil: um debate das relações entre saúde e trabalho. Cadernos de Saúde Pública, v. 22, p. 975-985, 2006.

MEDEIROS, J. A. D.; RODRIGUES, Celso Luiz Pereira. A existência de riscos na indústria da construção civil e sua relação com o saber operário. Encontro Nacional de Engenharia de produção, v. 21, 2001.

MORAES, L. D. Análise da aplicabilidade das normas regulamentadoras em obras de pequeno porte da construção civil. 2017.

SIRICHUK, K. G. Planejamento de obras de pequeno porte e curto prazo. 2013.

TAKAHASHI, M. A. B. et al. Precarização do Trabalho e Risco de Acidentes na construção civil: um estudo com base na Análise Coletiva do Trabalho (ACT). Saúde e Sociedade, v. 21, p. 976-988, 2012. 